$10-2011$

\title{
Exploration of NDE Properties of AMB Supported Rotors for Structural Damage Detection
}

Jerzy T. Sawicki

Cleveland State University, j.sawicki@csuohio.edu

Dmitry L. Storozhev

John D. Lekki

NASA Glenn Research Center, john.d.lekki@nasa.gov

Follow this and additional works at: https://engagedscholarship.csuohio.edu/enme_facpub

Part of the Mechanical Engineering Commons

How does access to this work benefit you? Let us know!

\section{Original Citation}

Jerzy T. Sawicki, Dmitry L. Storozhev, and John D. Lekki. (2011). Exploration of NDE Properties of AMB Supported Rotors for Structural Damage Detection. Journal of Engineering for Gas Turbines and Power, 133(10), 102501-102509, doi: 10.1115/1.4002908.

This Article is brought to you for free and open access by the Mechanical Engineering Department at EngagedScholarship@CSU. It has been accepted for inclusion in Mechanical Engineering Faculty Publications by an authorized administrator of EngagedScholarship@CSU. For more information, please contact library.es@csuohio.edu. 


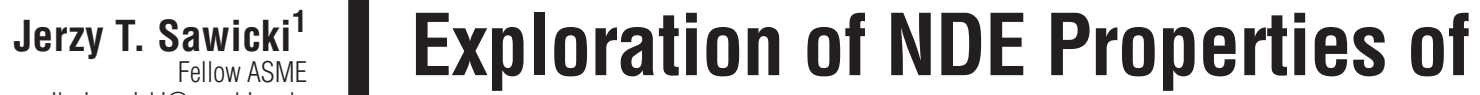 \\ e-mail: j.sawicki@csuohio.edu \\ Dmitry L. Storozhev ${ }^{2}$

\author{
Center for Rotating Machinery Dynamics and \\ Control (RoMaDyC), \\ Fenn College of Engineering, \\ Cleveland State University,
} \\ Cleveland, OH 44115-2214

\author{
John D. Lekki \\ NASA Glenn Research Center, \\ 21000 Brookpark Road, \\ Brookpark, OH 44135-3191 \\ e-mail: john.d.lekki@nasa.gov
} \\ AMB Supported Rotors for Structural Damage Detection \\ This paper addresses self-diagnostic properties of active magnetic bearing (AMB) sup- ported rotors for online detection of the transverse crack on a rotating shaft. In addition to pure levitation, the rotor supporting bearing also serves as an actuator that transforms current signals additionally injected into the control loop into the superimposed specially selected excitation forces into the suspended rotor. These additional excitations induce combination frequencies in the rotor response, providing unique signatures for the pres- ence of crack. The background of theoretical modeling, experimental, and computer simulation results for the AMB supported cracked rotor with self-diagnostic excitation forces are presented and discussed.}

\section{Introduction}

Recent advancements in actuator technology, power electronics, sensors, and signal processing have created a rapid development of smart machine technologies for rotating machinery [1,2]. Ranging from machine condition monitoring and diagnostics to full active control of machine behavior, the integration of electrical and computer systems has produced significant advances in machine performance and reliability.

Magnetic bearings are a typical mechatronics product. The hardware is composed of mechanical components combined with electronic elements such as sensors and power amplifiers and an information processing part, usually in the form of a microprocessor. In addition, an increasingly important part is software, which specifies the coordination of bearing forces to sensed rotor motion and consequently dictates the dynamic properties of the complete system. The inherent ability for sensing, information processing, and actuation gives the magnetic bearing the potential to become a key element in smart and intelligent machines.

\section{Background}

The equation of motion in fixed coordinates for the cracked rotor with the Mayes crack model can be written as [3-5]

$$
\mathbf{M} \ddot{\mathbf{q}}+(\mathbf{D}+\mathbf{G}) \dot{\mathbf{q}}+\mathbf{T}^{T} \tilde{\mathbf{K}}(\phi, t) \mathbf{T}\left(\mathbf{q}+\mathbf{q}_{\mathrm{st}}\right)=\mathbf{W}+\mathbf{F}_{\mathrm{un}}+\mathbf{F}_{\mathrm{ex}}(1 a)
$$
where

$$
\begin{gathered}
\tilde{\mathbf{K}}(\phi)=\left[\begin{array}{cc}
\tilde{k}_{\alpha \alpha}(\phi) & 0 \\
0 & \tilde{k}_{\beta \beta}(\phi)
\end{array}\right] \\
\tilde{k}_{\alpha \alpha}(\phi)=0.5\left(k_{0}+k_{\alpha}\right)+0.5\left(k_{0}-k_{\alpha}\right) \cos \phi \\
\tilde{k}_{\beta \beta}(\phi)=0.5\left(k_{0}+k_{\beta}\right)+0.5\left(k_{0}-k_{\beta}\right) \cos \phi
\end{gathered}
$$

and $\mathbf{W}, \mathbf{F}_{\text {un }}$, and $\mathbf{F}_{\mathrm{ex}}$ are the gravitational force, the unbalance forces, and the external excitation forces applied to the rotor by the active magnetic force actuator, respectively; $\mathbf{M}, \mathbf{D}$, and $\mathbf{G}$ are the matrices of mass, damping, and gyroscopic, respectively. The

\footnotetext{
${ }^{1}$ Corresponding author.

${ }^{2}$ Currently at GE Energy; e-mail: dmitry.storozhev@ge.com
}

above stiffness matrix $\tilde{\mathbf{K}}$ has been designed in a rotating coordinate system $0 \alpha \beta$, where $k_{\mathrm{o}}$ is the uncracked stiffness of the axisymmetric rotor (the crack is fully closed) while $k_{\alpha}$ and $k_{\beta}$ represent the stiffness of the cracked rotor with a fully open crack in the $\alpha$ and $\beta$ directions, respectively. Lastly, $\phi=\Omega t+\phi_{0}$ is the angle between the crack axis and the rotor response at the crack location and $\mathbf{T}$ is the transformation matrix from rotating to inertial coordinates.

Assuming weight dominance or $\left|\mathbf{q}_{s t}\right| \gg|\mathbf{q}|$ and taking into account that $\mathbf{K}_{0} \mathbf{q}_{\text {st }}=\mathbf{W}$, one can obtain the parametrically excited cracked rotor model in fixed coordinates system as follows $[3,4,6]$ :

$$
\mathbf{M} \ddot{\mathbf{q}}+(\mathbf{D}+\mathbf{G}) \dot{\mathbf{q}}+\left[\mathbf{K}_{0}-\Delta \mathbf{K}(t)\right] \mathbf{q}=\mathbf{F}_{\mathrm{un}}+\mathbf{F}_{\mathrm{ex}}
$$

with

$$
\mathbf{K}_{0}=\left[\begin{array}{cc}
k_{0} & 0 \\
0 & k_{0}
\end{array}\right], \quad \Delta \mathbf{K}(t)=\left[\begin{array}{ll}
k_{11} & k_{12} \\
k_{21} & k_{22}
\end{array}\right]
$$

where the matrices $\mathbf{K}_{0}$ and $\Delta \mathbf{K}(t)$ represent the undamaged shaft stiffness and the periodic function of time representing the stiffness change due to crack, respectively. In fixed coordinates, the above model produces a response at $1 \mathrm{X}, 2 \mathrm{X}$, and $3 \mathrm{X}$ synchronous components as long as no other nonlinearities are present in the system $[3,4]$.

Currently, there are two widely accepted industrial approaches for rotor crack detection. One includes monitoring of the changes in amplitude and phase of the synchronous response, and the other one is based on watching for the occurrence of $2 \mathrm{X}$ vibrations, especially when the rotor runs near the half of any balance resonance speed. Application of conventional nondestructive evaluation (NDE) methods is very limited due to their unacceptable limits. Some of these techniques are time-consuming and inconvenient for turbomachinery service testing. Almost all of these techniques require that the vicinity of the damage to be known in advance, and they can only provide local information and no indication of the structural strength at a component and/or system level. Also, the effectiveness of these experimental techniques is affected by the high measurement noise levels existing in complex turbomachine structures. It should be noted that for the rotor with breathing crack described by Eq. (2), the modal testing is ineffective in identification of crack since such rotor behaves as a nonlinear time varying system. 
This paper explores NDE properties of rotors supported on magnetic bearings based on novel application of built-in actuation and diagnostics capabilities of AMB utilized for online detection of the shaft transverse crack.

2.1 Application of Active Magnetic Bearing for Crack Detection. The key aspect of utilization of NDE properties of AMB supported rotors is based on the fact that the system has three different classes of frequencies, namely, the natural frequencies (or critical speeds), rotor spin speeds, and the forcing frequencies from the AMB. The parametric terms in the equations of motion (Eq. (2)) induce combinational frequencies in the response of the machine. Mani et al. [7] used a multiple scales analysis to determine the conditions required for a combinational resonance, which occurs when

$$
\Omega_{e}=\left|n \Omega-\omega_{i}\right| \text { for } n= \pm 1, \pm 2, \pm 3, \ldots
$$

where $\Omega$ is the rotor spin speed, $\Omega_{e}$ is the frequency of the AMB diagnostic excitation force, and $\omega_{i}$ is a natural frequency of the system. This analysis was based on a two degree of freedom Jeffcott rotor model with weight dominance. The multiple scales approach seems to provide good results although the extension to complex systems with more than one resonance is difficult $[6,8]$. It should also be noted that there are AMB excitation frequencies that do not satisfy Eq. (4) but produce responses containing combinations of the rotor spin speed and AMB excitation frequency. Indeed, any situation where the external excitation frequency, rotor spin speed, and natural frequency are linearly related with integer coefficients is likely to produce a significant response.

\section{Experimental Study}

3.1 Experimental Apparatus. The photo and the basic dimensions of the experimental rotor test rig employed in this study are shown in Figs. 1(a) and 1(b), respectively. The facility was described in detail in Refs. [9-12]. The rig is equipped with conical AMBs, which serve as rotor supporting bearings as well as actuators for injection of the specified excitation harmonic force. The eight-pole radial design bearings are equipped with four variable reluctance-type position sensors. The magnetic force is applied to the rotor along two perpendicular V's, W-axes, which are rotated 45 deg from the vertical.

The solid shaft with a diameter of $15.875 \mathrm{~mm}$ and a length of $659 \mathrm{~mm}$ is made of 400 series hardened stainless steel. The conical rotors of AMBs have a $13 \mathrm{deg}$ cone angle, and its diameter at the center of actuation is $42.9 \mathrm{~mm}$. The 48 finite element model of the rotor presented in Fig. 1(c) shows the position of the supporting magnetic bearings (at nodes 4 and 42), the position of external force injection (node 4), and the position of sensing (node 8) used for crack detection signal processing. The disk with a diameter of $127 \mathrm{~mm}$, a thickness of $30.5 \mathrm{~mm}$, and a mass of $3.18 \mathrm{~kg}$ is located at the 22nd station, at the midspan of supporting bearings (see Fig. $1(c))$.

For the operating conditions corresponding to the tested cases, the equivalent stiffness and damping of the magnetic bearings were calculated to be about $2 \times 10^{5} \mathrm{~N} / \mathrm{m}$ and $500 \mathrm{~N} \mathrm{~s} / \mathrm{m}$, respectively. The calculated natural frequencies of the considered active rotor-bearing system are $29.7 \mathrm{~Hz}$ and $70.6 \mathrm{~Hz}$ (the rigid body or bearing modes) and $102.1 \mathrm{~Hz}$ (first flexible mode), and they all agreed well with the experimental results. The undamped critical speed map for this system is presented in Fig. 2.

A small notch approximating a breathing crack was cut using a wire electric discharge machine (EDM) with the wire diameter of $0.1016 \mathrm{~mm}$ (0.004 in.). For the considered cases, two cracked shafts were tested, with $25 \%$ and $40 \%$ of the shaft diameter crack depth. The EDM notch was located at the distance of $275 \mathrm{~mm}$ from the center of nondrive end magnetic bearing (at node 4, Fig. $1(c)$ ). In theory, an actual crack would have a zero width; therefore, a stainless steel shim was inserted into the $25 \%$ and $40 \%$ EDM cuts in order to ensure the opening and closing behaviors of

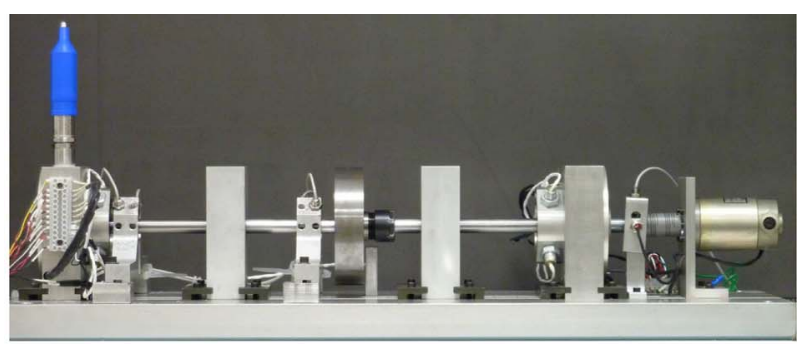

(a)

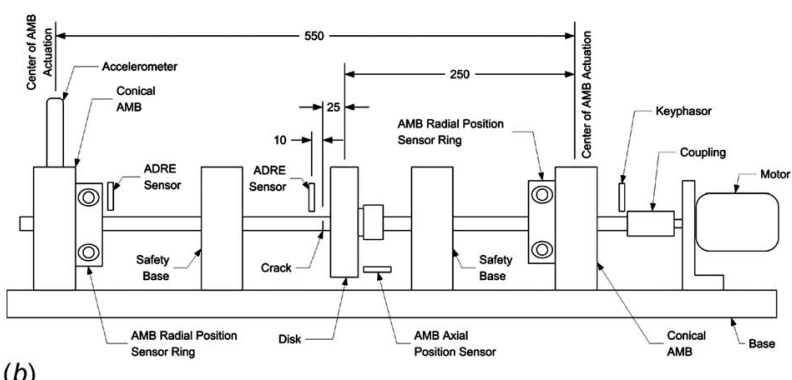

(b)

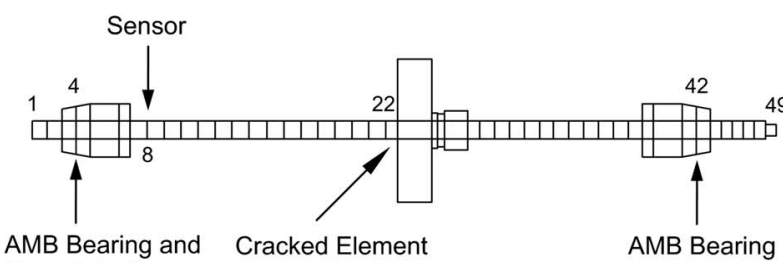

Force Injection

(c)

Fig. 1 (a) Photo of experimental test rig, (b) schematic with dimensions in [mm], (c) finite element model of the rotor

the real crack as close as possible. Magnified images of the EDM cut without and with the inserted shim are shown in Figs. 3(a) and $3(b)$, respectively.

It is known that the breathing action of the crack is restricted only to the weight dominated rotors, i.e., when static deflection is greater than the rotor response due to unbalance. Finite element analysis was employed in this study to estimate the rotor static deflection to be about $160 \mu \mathrm{m}$, see Fig. 4, which is much larger

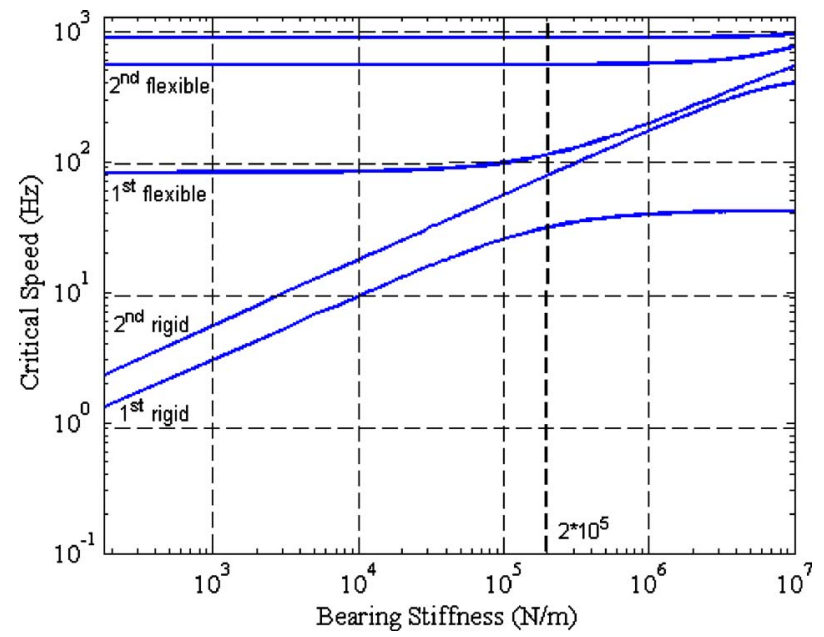

Fig. 2 Undamped critical speed map for AMB rotor system 


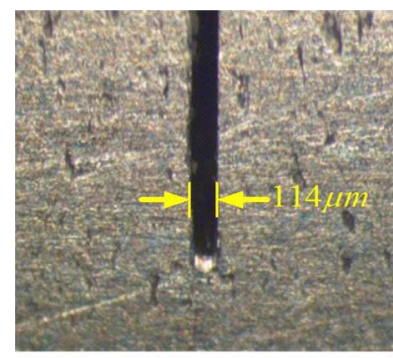

(a)

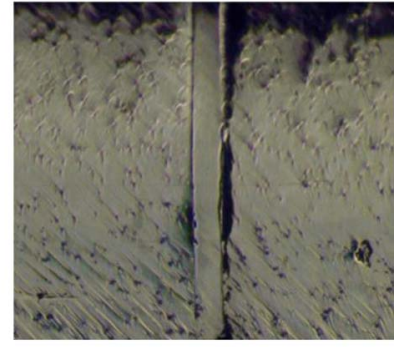

(b)
Fig. 3 Magnified view of the shaft with EDM cut: (a) with no shim and $(b)$ with an inserted shim

than the experimentally measured peak amplitude of the $40 \%$ cracked rotor response (approximately $70 \mu \mathrm{m}$ ).

3.2 Controller Design and AMB Force Injection. Following the modeling campaign of all the components of the AMB rotor system, a proportional-integral-derivative (PID) controller with notch and low pass filters was developed and implemented at 10 $\mathrm{kHz}$ to provide a stable and quiet rotor levitation at the given spin speed. The model of the controlled AMB rotor system was built in SIMULINK (see Fig. 5) and implemented via DSPACE rapid proto-

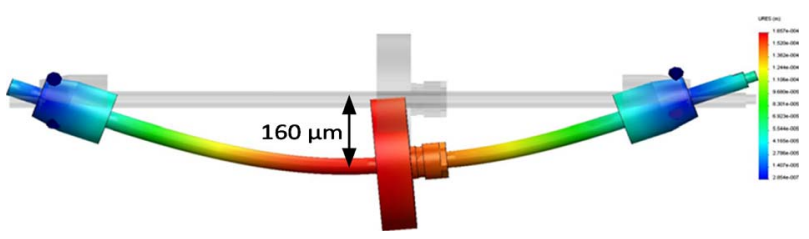

Fig. 4 Static deflection of the rotor due to its weight

typing system.

The overall transfer function of the controller, which consists of all the above components connected in series, can be expressed as

$$
G(s)=G_{\mathrm{PID}}(s) G_{\mathrm{LP}}(s) G_{N}(s) K_{T}
$$

where $K_{T}$ is a total gain of the controller that works as a scaling factor for the entire control loop and $G_{\mathrm{LP}}$ and $G_{N}$ are the transfer functions of low pass and notch filters, respectively. Figure 6 illustrates the transfer functions of the developed PID controller for one control axis. Since the system is axisymmetric, the controllers are identical in each axis of the system.

Figure 7 presents the simulated (Fig. 7(a)) and measured (Fig. $7(b))$ orbits of the levitated rotor running at a speed of $1560 \mathrm{rpm}$ $(26 \mathrm{~Hz})$ without (top row) and with (bottom row) external harmonic excitation force. The orbits apply to the rotor motion due to

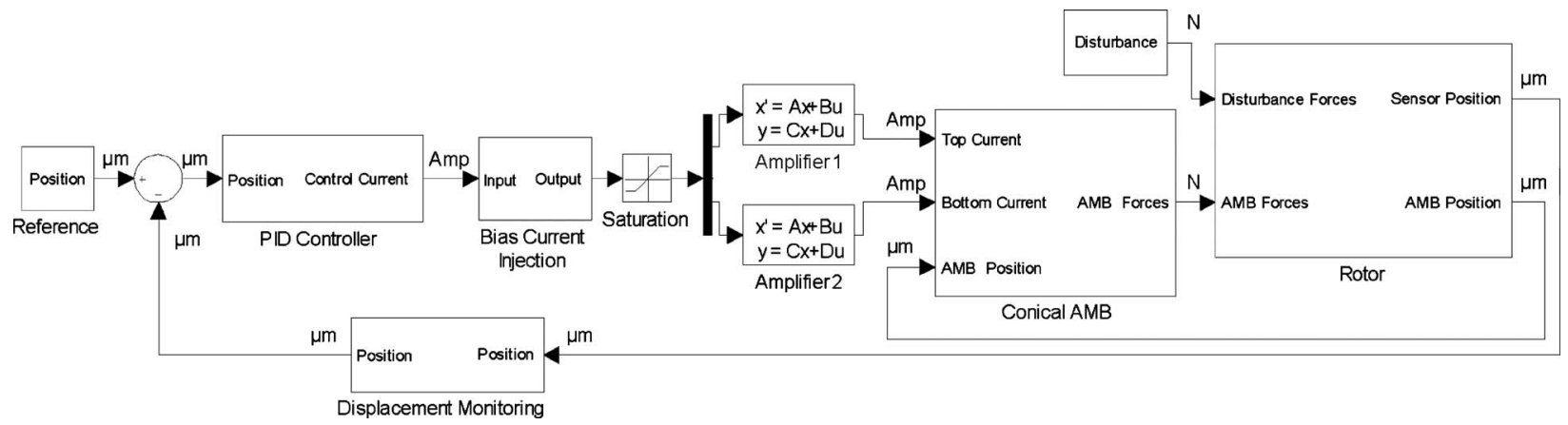

Fig. 5 sIMULINK model of the rotor supported on conical AMBs
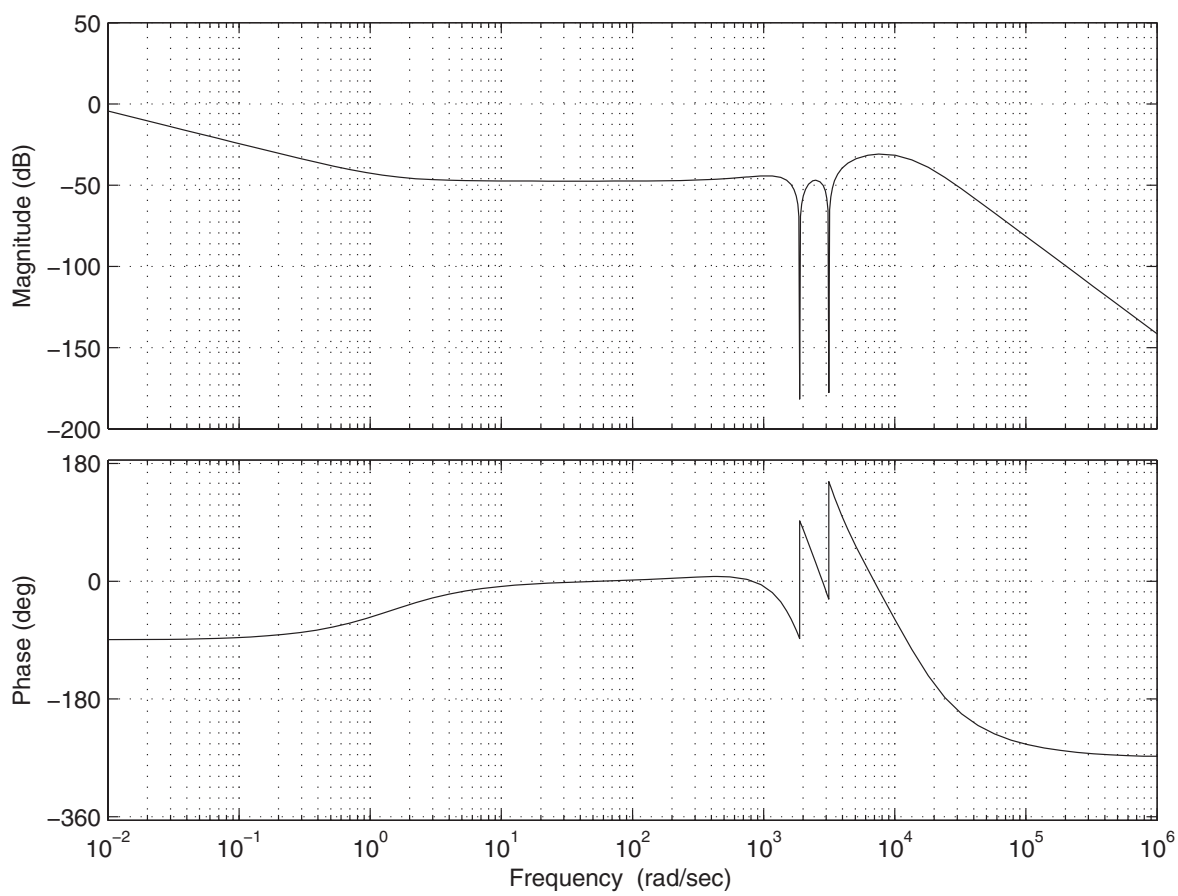

Fig. 6 Transfer function for single axis for the developed controller 

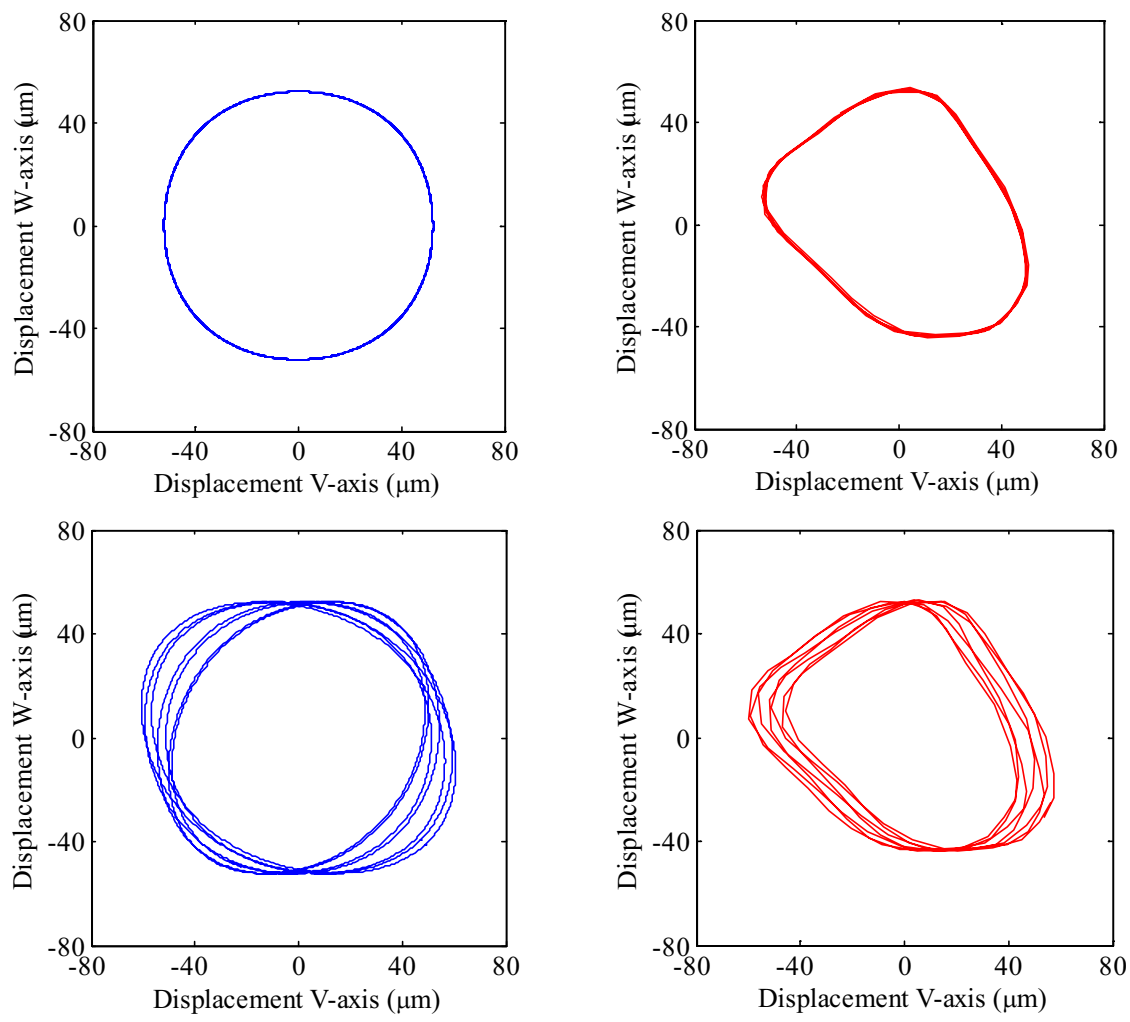

(a)

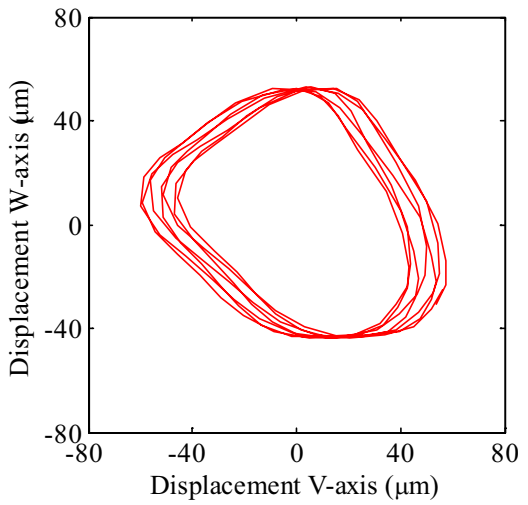

(b)

Fig. 7 (a) Simulated and (b) experimental orbits of the uncracked rotor supported on conical AMBs at spin speed of $\omega=1560 \mathrm{rpm}$ without (top row) and with (bottom row) force injection

residual unbalance measured at the bearings midspan at node 22 (see Fig. $1(c)$ ), and the excitation force of $5 \mathrm{~N}$ and frequency of $18.6 \mathrm{~Hz}$ were applied at node 4 . The simulated orbits were produced by the model shown in Fig. 5, which includes PID controller with the transfer function presented in Fig. 6. It can be noticed that the orbits are similar although the amplitudes of the modeled vibrations are slightly overestimated regardless of the presence of excitation force. It can be noticed that for the given running speed, the experimentally measured rotor dynamic response (Figs. 7(b)) is well below the estimated static deflection (Fig. 4), which ensures the breathing action of the crack.

The harmonic force excitation was generated by the current injection that was superimposed on the levitation current (i.e., bias plus control current) in one axis of the nondrive end magnetic
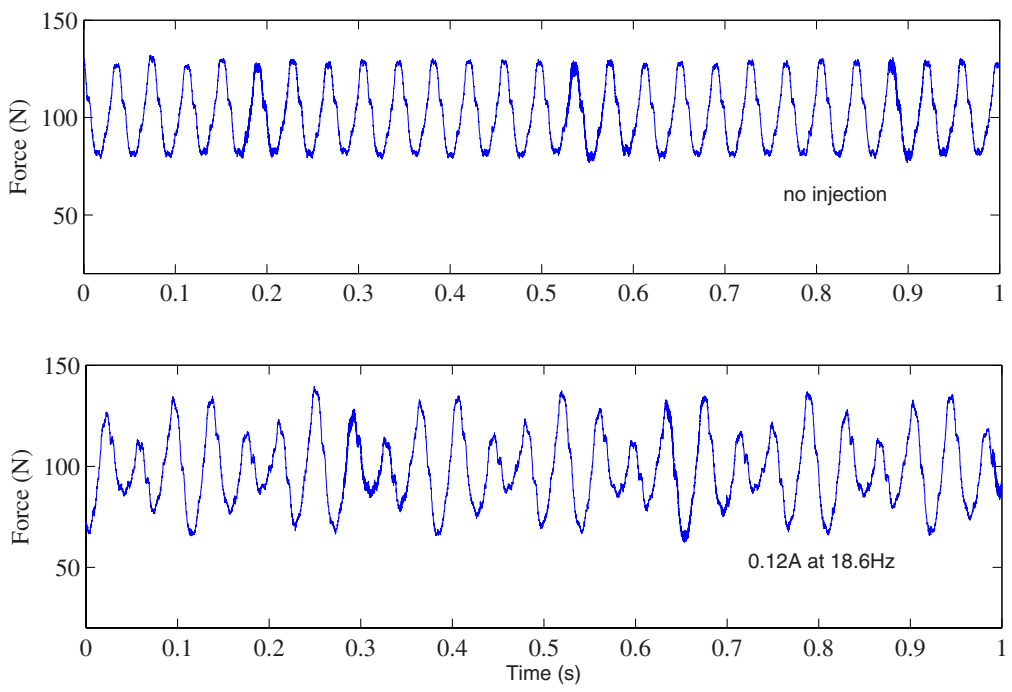

Fig. 8 Measured total magnetic force in one axis of the nondrive bearing without and with excitation force 


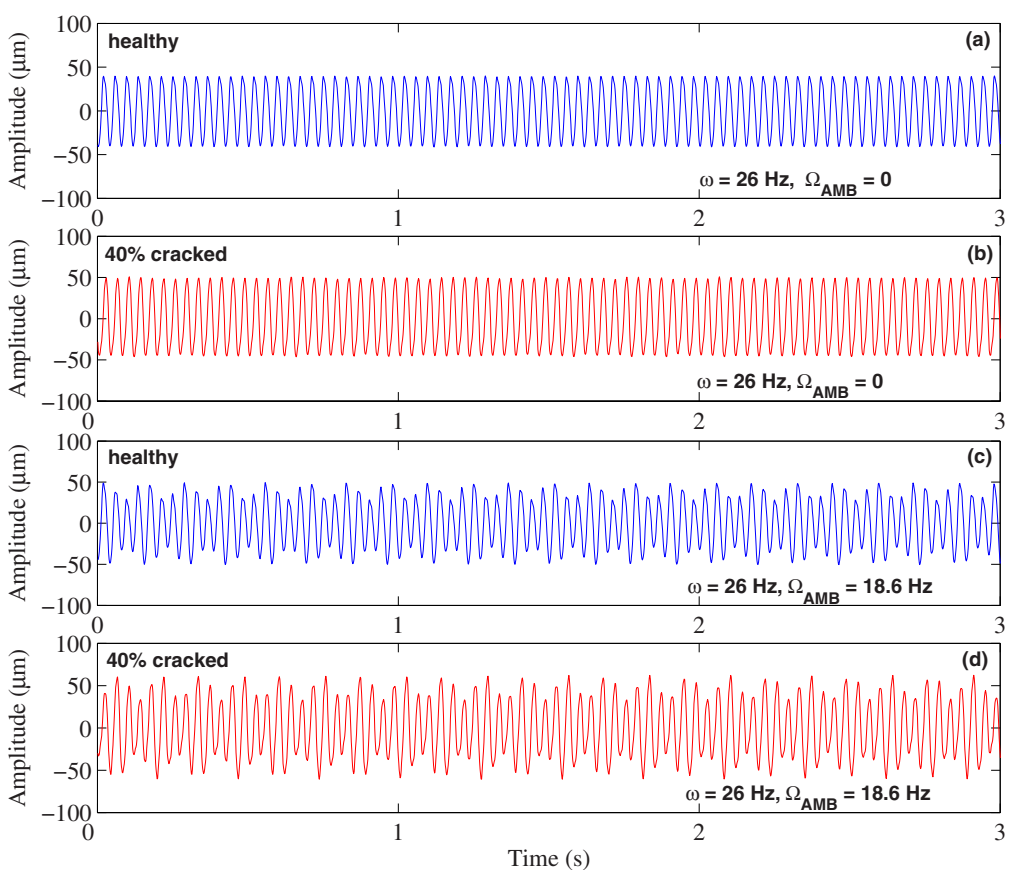

Fig. 9 Experimental time responses of the healthy and $40 \%$ cracked rotors running at $1560 \mathrm{rpm}$ without $((a)$ and $(b))$ and with $((c)$ and $(d))$ external excitation force of $5 \mathrm{~N}$ at $18.6 \mathrm{~Hz}$ applied at $\mathrm{W}$-axis of a nondrive end bearing

bearing. The total current and position data were collected, and the force on the rotor axis was calculated online using the following formula:

$$
F_{\mathrm{AMB}}=C \times\left[\left(\frac{I_{\text {top }}}{2(g-x)}\right)^{2}-\left(\frac{I_{\text {bot }}}{2(g+x)}\right)^{2}\right] \times 10^{6}(\mathrm{~N})
$$

where $F_{\mathrm{AMB}}$ is the force on axis $(\mathrm{N}), C$ is the calibration factor
( $\left.\mathrm{N} \mu \mathrm{m}^{2} / \mathrm{A}^{2}\right), I_{\text {top }}$ and $I_{\text {bot }}$ are the measured currents on the top and bottom coils (A), respectively, $g$ is the effective gap between the magnet and the rotor $(401.55 \mu \mathrm{m})$, and $x$ is the rotor displacement measured by the control system $(\mu \mathrm{m})$.

Figure 8 shows the measured online total AMB force in single axis of AMB without (top) and with (bottom) force injection.
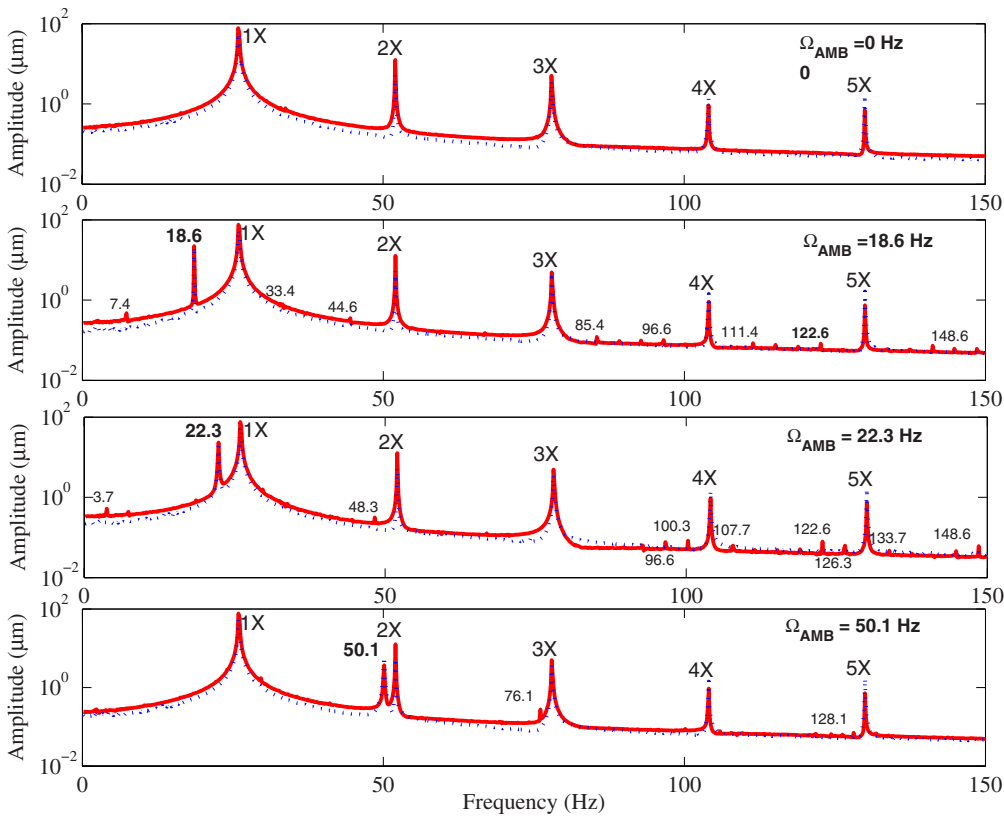

Fig. 10 Comparison between experimental frequency responses of the healthy (dotted line) and $25 \%$ cracked (solid line) rotors at spin speed of $\omega=26 \mathrm{~Hz}$ and excitation force of $5 \mathrm{~N}$ with various frequencies, measured at the nondrive end bearing 


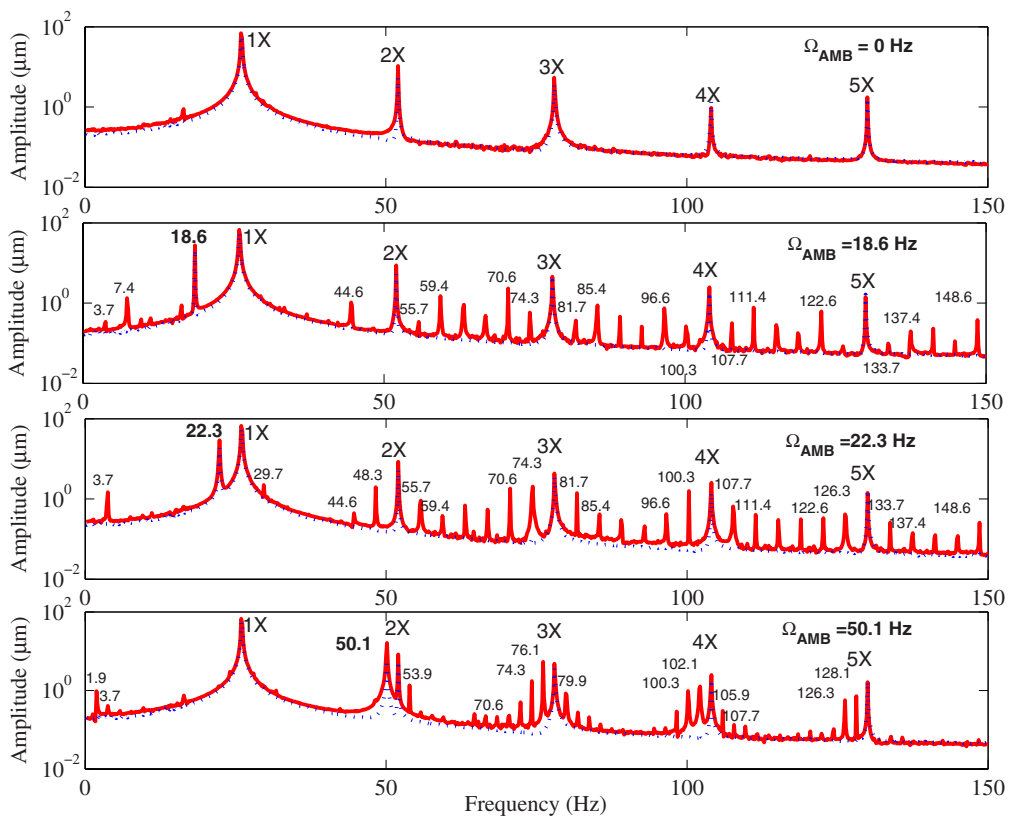

Fig. 11 Comparison between experimental frequency responses of the healthy (dotted line) and $40 \%$ cracked (solid line) rotors at spin speed of $\omega=26 \mathrm{~Hz}$ and excitation force of $5 \mathrm{~N}$ with various frequencies, measured at the nondrive end bearing

Here, only the injection of $0.12 \mathrm{~A}$ at $18.6 \mathrm{~Hz}$ has been shown for illustrative purposes.

3.3 Experimental Results. For all presented experimental results, the rotor was levitated on AMBs and spinning at a constant speed of $1560 \mathrm{rpm}(26 \mathrm{~Hz})$. In all test cases, the cracked rotor involved the shimmed EDM cut, as it was discussed previously. The experimental time series of measured displacement, in the direction of $45 \mathrm{deg}$ from vertical one, for the cracked and healthy rotors are presented in Fig. 9.

One can notice some increase in the cracked rotor response amplitude. More sophisticated changes can be seen in Figs. 9(c) and $9(d)$, where the healthy (Fig. $9(c)$ ) and cracked (Fig. $9(d)$ ) rotors are subjected to the magnetic actuator applied harmonic force having amplitude of $5 \mathrm{~N}$ peak-to-peak (p-p) and fixed frequency of $18.6 \mathrm{~Hz}[13,14]$.

Experimentally measured at the nondrive end bearing (sensor

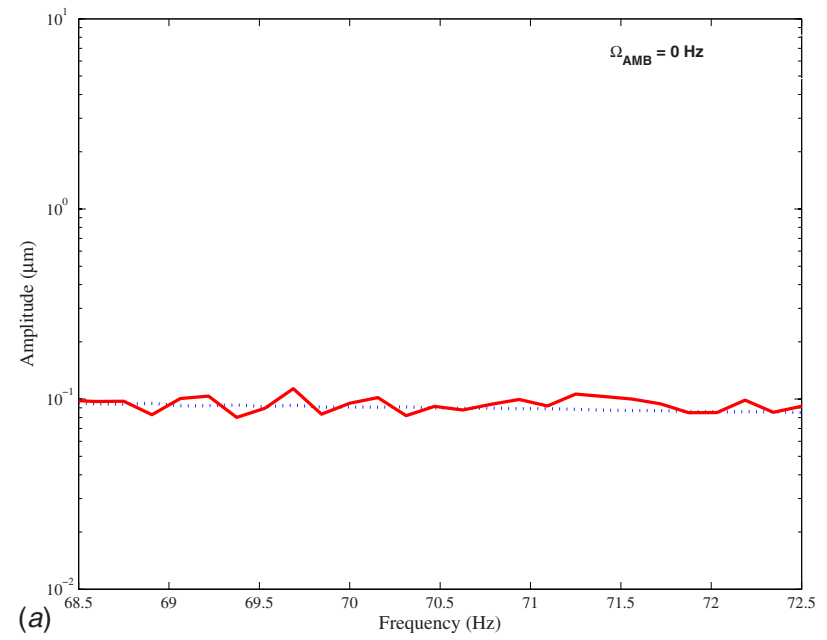

located at node 8, see Fig. 1(c)) frequency responses for the uncracked (healthy) and 25\% cracked rotors are illustrated in Fig. 10. The presented spectra are for different AMB excitation force frequencies calculated based on different mode frequencies using the formula in Eq. (4). Thus, the excitation frequency of $18.6 \mathrm{~Hz}$ was calculated using the second rigid body mode $(70.6 \mathrm{~Hz}), 22.3$ $\mathrm{Hz}$ using the first rigid mode $(29.7 \mathrm{~Hz})$, and $50.1 \mathrm{~Hz}$ using the first flexible mode $(102.1 \mathrm{~Hz})$ with $n=2$ for all cases. It can be seen that in this case, the measured frequency responses are almost identical for the uncracked and $25 \%$ cracked rotors although one can notice a slightly higher overall amplitude for the cracked rotor case. The spectra show response at synchronous frequency and its integer multiples and, in the presence of the AMB forcing, also the excitation frequency. For excitation frequencies of $18.6 \mathrm{~Hz}$ and $22.3 \mathrm{~Hz}$, there can be noticed incipience of combinational frequencies; however, they are not of sufficient amplitude to draw

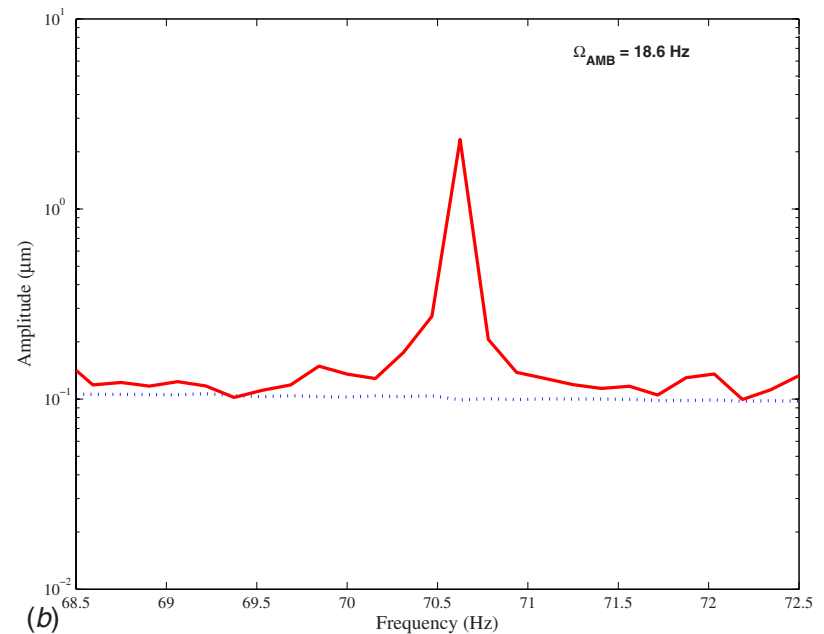

Fig. 12 Experimental frequency responses of the healthy (dotted line) and $40 \%$ cracked (solid line) rotors at spin speed of $\omega=26 \mathrm{~Hz}(a)$ without and (b) with excitation force of $5 \mathrm{~N}$ near the combinational frequency of $70.6 \mathrm{~Hz}$ 

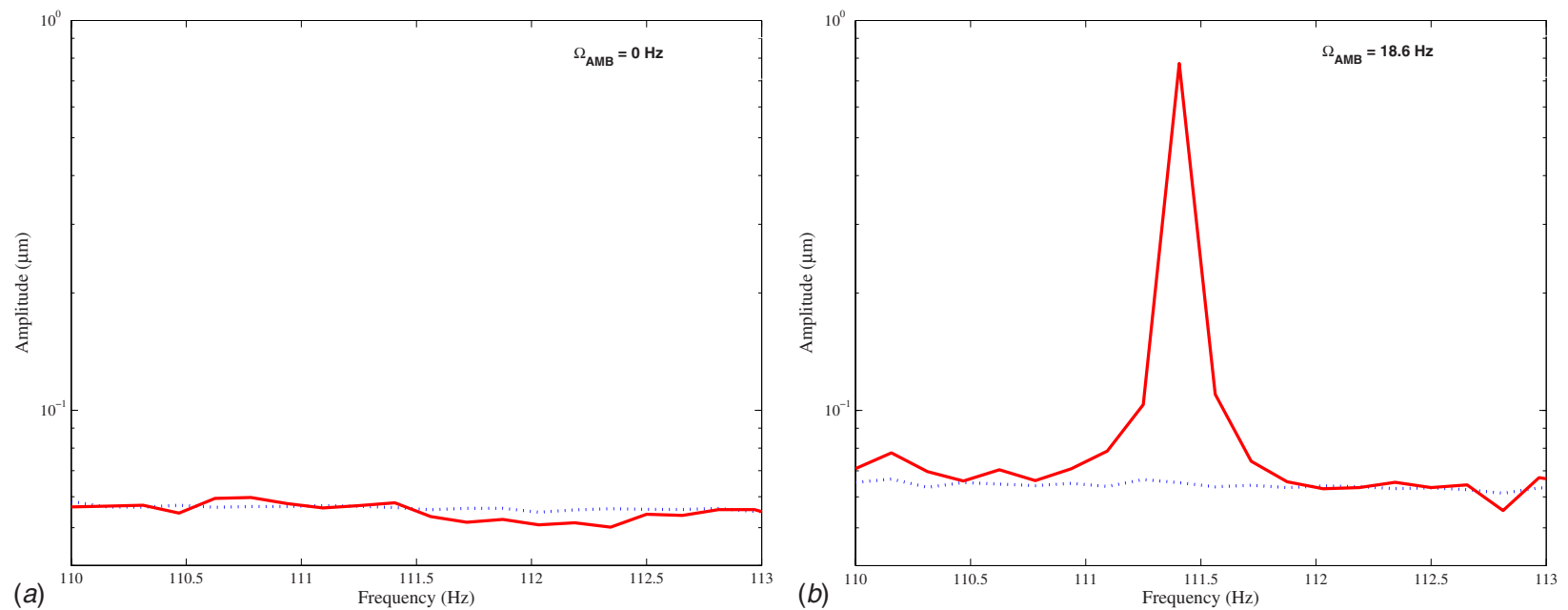

Fig. 13 Experimental frequency responses of the healthy (dotted line) and $40 \%$ cracked (solid line) rotors at spin speed of $\omega=26 \mathrm{~Hz}($ a) without and (b) with excitation force of $5 \mathrm{~N}$ near the combinational frequency of $111.4 \mathrm{~Hz}$

any constructive conclusions.

Figure 11 shows the comparison of the experimentally extracted frequency responses for the uncracked and $40 \%$ cracked rotors measured at the same location and subjected to the same excitation frequencies as in Fig. 10. Here, the scenario is quite different than in a previously considered case. In the case of no AMB excitation, the only response can be seen at the rotor spin speed and its harmonics, and its amplitudes are higher for the cracked rotor. Application of nonzero frequency excitation force induces the cracked rotor responses at combinational frequencies, as defined by Eq. (4) in Sec. 3.2. For example, in the case of excitation frequency of $18.6 \mathrm{~Hz}$, the following combination frequencies are induced: $7.4 \mathrm{~Hz}, 44.6 \mathrm{~Hz}, 55.7 \mathrm{~Hz}, 59.4 \mathrm{~Hz}, 70.6 \mathrm{~Hz}$, 74.3 Hz, 811.7 Hz, 85.4 Hz, 96.6 Hz, 111.4 Hz, 122.6 Hz, and $137.4 \mathrm{~Hz}$, in addition to synchronous response and its integer multiples. Similar sets (following Eq. (4)) can be found and experimentally verified for other excitation frequency values. In all cases, the response amplitudes for the cracked rotor at the combination frequencies are significantly higher in the presence of external excitation.

In order to better illustrate the significance of the experimental results presented in Fig. 11, the rotor responses at the close vicinity of $70.6 \mathrm{~Hz}$ and $111.4 \mathrm{~Hz}$ are shown in Figs. 12 and 13, respectively, for a case without (a) and with (b) AMB excitation. The considerable magnification of the cracked rotor response due to AMB excitation is transparent. A similar behavior can also be observed at other combinational frequencies.

Since most rotating machinery has installed acceleration transducers mounted on the bearing housings, the effort was made to evaluate feasibility of the presented crack detection approach for this type of transducer and its placement. The Bently-Nevada ${ }^{\circledR}$ 330400 accelerometer [15] was mounted on the nondrive bearing housing, as is illustrated in photo in Fig. 1(a). Figure 14 shows the frequency responses for the uncracked and cracked rotors mea-

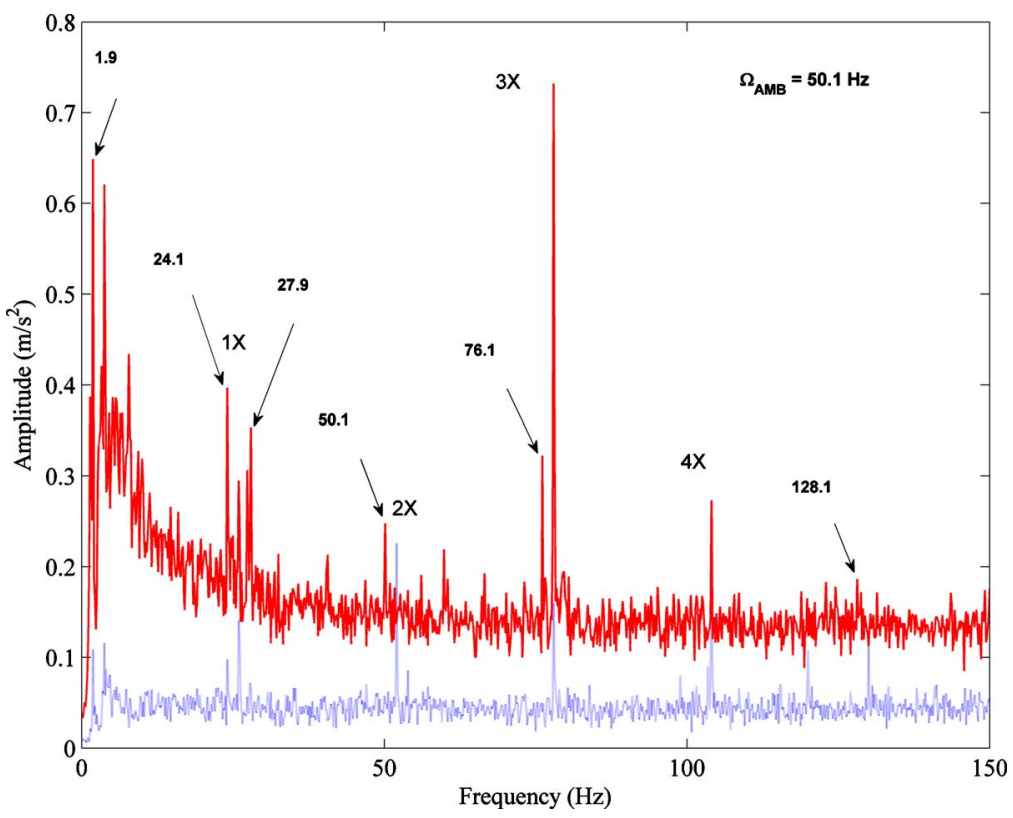

Fig. 14 Experimental responses of the healthy (dotted line) and $40 \%$ cracked (solid line) rotors at spin speed of $\omega=26 \mathrm{~Hz}$ with excitation force of $5 \mathrm{~N}$ at $50.1 \mathrm{~Hz}$ measured with accelerometer mounted on nondrive end bearing housing 

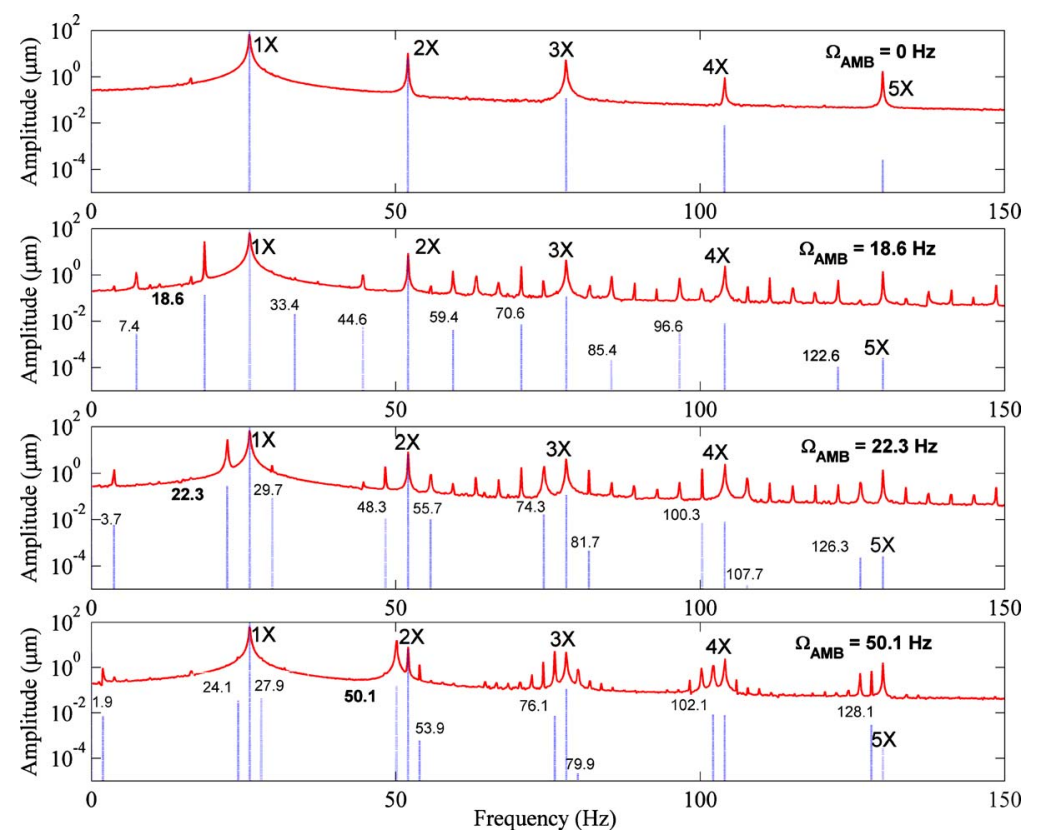

Fig. 15 Comparison between simulated (dotted line) and experimental (solid line) frequency responses of the $40 \%$ cracked rotor at spin speed of $\omega=26 \mathrm{~Hz}$ and excitation force of $5 \mathrm{~N}$ with various frequencies measured at the nondrive end bearing

sured by the accelerometer mounted on the nondrive end bearing in the presence of harmonic force excitation at $50.1 \mathrm{~Hz}$ and amplitude of $5 \mathrm{~N}$. Over the whole frequency range, the overall amplitude of the cracked rotor response is higher than that of the uncracked rotor, and the set of combination frequencies, as defined by Eq. (4), can also be noticed. These experimental results provide evidence that there exists potential for the proposed approach to be applied based on readout directly from accelerometers mounted on bearing housings.

Finally, a direct comparison of computer simulation results and the experimental data are presented in Fig. 15. These comparisons use the $40 \%$ shimmed levitated cracked shaft running at $1560 \mathrm{rpm}$ with $\mathrm{AMB}$ injection frequencies of $0 \mathrm{~Hz}, 18.6 \mathrm{~Hz}, 22.3 \mathrm{~Hz}$, and $50.1 \mathrm{~Hz}$ shown in the corresponding plots. In simulation, the breathing model for the cracked shaft finite element was based on fracture mechanics approach [16]. Each plot in Fig. 15 has denoted major response frequencies, and one can notice that the simulation results closely resemble the experimental data. The major frequency components match very well, specifically the running speed and its multiples, AMB signal injection, natural frequency, and the major combination frequencies. It can be also noticed that for higher values of excitation frequency, experimental responses show tendency for frequency components to be clustered around integer multiples of synchronous response.

\section{Conclusions}

The presented experimental and simulation results show that the use of an active magnetic bearing to apply specified force excitation to the rotor has the potential in diagnostics of structural damage of rotors. When the rotor system is interrogated by harmonic force, the combination frequencies based on the AMB frequency, the rotational speed, and the natural frequencies are induced, which can be used to detect damage. The important aspect is that in a case of AMB supported machines, no extra actuators are required. Also, the processed data for online crack detection was taken at bearing location while the crack was near the center between the bearings.

Although AMB technology seems to lend itself naturally to the role of calibrated actuator or force transducer, accuracy limits can be significant. However, these accuracy issues seen in other applications have relatively little impact here, where the primary interest is in quantitative frequencies and qualitative (especially relative) amplitudes. That is, the frequencies of data retrieved from the AMB will be quite accurate, and the absolute amplitudes may suffer from calibration issues but relative amplitude-especially over narrow frequency ranges-will also be accurate.

\section{Acknowledgment}

This research has been funded by NASA's "Research Opportunities in Aeronautics," Grant No. NNX08AC31A.

\section{References}

[1] Maslen, E. H., 2008, "Smart Machine Advances in Rotating Machinery," 9th International Conference on Vibrations in Rotating Machinery, IMechE, Exeter, UK, Sept. 8-10.

[2] Larsonneur, R., and Richard, P., 2008, "Smart Turbomachines Using Active Magnetic Bearings," ASME Paper No. GT2008-51299.

[3] Penny, J. E. T., Friswell, M. I., and Zhou, C., 2006, "Condition Monitoring of Rotating Machinery Using Active Magnetic Bearings," ISMA 2006, Leuven, Belgium, pp. 3497-3506.

[4] Penny, J. E. T., and Friswell, M. I., 2007, "The Dynamics of Cracked Rotors," IMAC XXV, Orlando, FL, Paper No. 198, 2007.

[5] Mayes, I. W., and Davies, W. G. R., 1984, "Analysis of the Response of a Multi-Rotor-Bearing System Containing a Transverse Crack in a Rotor," ASME J. Vib., Acoust., Stress, Reliab. Des., 106, pp. 139-145.

[6] Sawicki, J. T., Friswell, M. I., Pesch, A. H., and Wroblewski, A., 2008, "Condition Monitoring of Rotor Using Active Magnetic Actuator," ASME Paper No. GT2008-51169.

[7] Mani, G., Quinn, D. D., and Kasarda, M., 2006, "Active Health Monitoring in a Rotating Cracked Shaft Using Active Magnetic Bearings as Force Actuators," J. Sound Vib., 294, pp. 454-465.

[8] Ishida, Y., and Inoue, T., 2006, "Detection of a Rotor Crack Using a Harmonic Excitation and Nonlinear Vibration Analysis," ASME J. Vibr. Acoust., 128, pp. 741-749.

[9] Sawicki, J. T., and Lekki, J. D., 2008, "Smart Structural Health Monitoring of Rotating Components Using Active Magnetic Force Actuators," NASA Aviation Safety Technical Conference, Denver, CO, Oct. 21-23.

[10] Sawicki, J. T., 2009, "Rotor Crack Detection Using Active Magnetic Bearings," Solid State Phenom., 144, pp. 9-15. 
[11] Sawicki, J. T., Sen, A. K., and Litak, G., 2009, "Multiresolution Wavelet Analysis of the Dynamics of a Cracked Rotor," Int. J. Rotating Mach., 2009 p. 265198.

[12] Storozhev, D. L., 2009, "Smart Rotating Machines for Structural Health Monitoring," MS thesis, Cleveland State University, Cleveland, OH.

[13] Litak, G., and Sawicki, J. T., 2009, "Intermittent Behaviour of a Cracked Rotor in the Resonance Region," Chaos, Solitons Fractals, 42, pp. 1495-1501.
[14] Litak, G., Sawicki, J. T., and Kasperek, R., 2009, "Cracked Rotor Detection by Recurrence Plots," Nondestr. Test. Eval., 24(4), pp. 347-351.

[15] http://www.gepower.com/prod_serv/products/oc/en/downloads/141638K1.pdf

[16] Wu, X., Sawicki, J. T., Friswell, M. I., and Baaklini, G., 2005, "Finite Element Analysis of Coupled Lateral and Torsional Vibration of a Rotor With Multiple Cracks," ASME Paper No. GT2005-68839. 